\title{
Young People's Experiences of Violence and Abuse in Same-sex Relationships: Understandings and Challenges
}

\author{
Carolina Øverlien* \\ Norwegian Center for Violence and Traumatic Stress Studies (NKVTS) \\ Dept. of Social Work, Stockholm University \\ Email: carolina.overlien@nkvts.no
}

\begin{abstract}
Studies on youth intimate partner violence (IPV) issues have been increasingly published during the last few years. However, research on IPV in same-sex relationships among youths is limited. The aim of this article is to expand this knowledge base by exploring the voices of four youth exposed to IPV in same-sex relationships, investigating the similarities to violence in heterosexual relationships and shedding light on the complicating factor of sexuality. The Listening Guide analysis used in this article reveals that, although the dynamics of YIPV are similar to heterosexual relationships, participants experience responses from their immediate social network that reflect heteronormativity and homophobia, and result in participants' feeling like a burden. Furthermore, the findings of the analysis show that dominant social discourses on men's violence against women may become barriers to help-seeking. Thus, professionals need to gain knowledge of the unique challenges experienced by sexual minority youths exposed to IPV to prevent the issue and support those that experience it. Moreover, qualitative researchers need to further develop an understanding of the lives of youths exposed to IPV in same-sex relationships.
\end{abstract}

Keywords: same-sex relationship, youth intimate partner violence, listening guide analysis, heteronormativity, LGBT, homophobia 


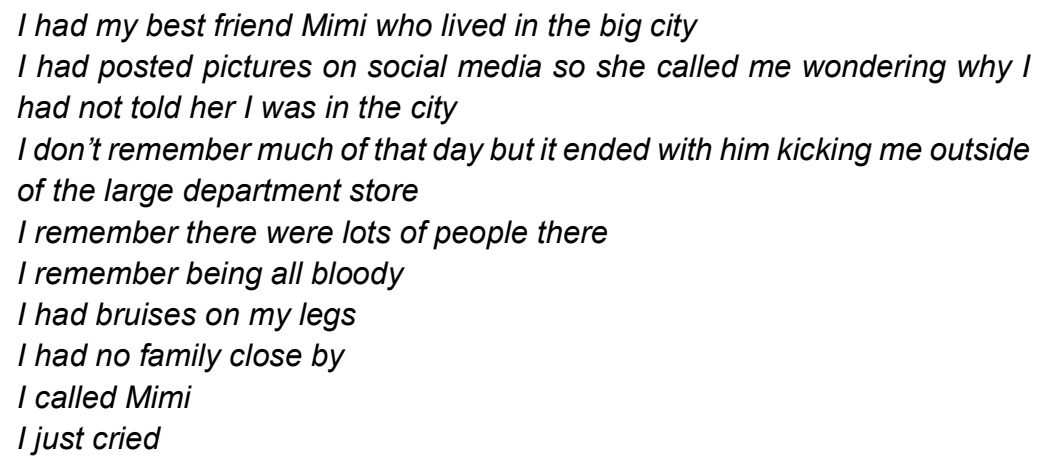

The 'I-poem' above is from a research interview with Magnus, a 21-year-old young male who experienced severe violence and abuse from his former boyfriend. The poem is applied in the analytical method used in the project reported in this article. Furthermore, the poem shows how young people in same-sex relationships can become victims of intimate partner violence (IPV) and that IPV can take place in the midst of all us such, such as on a busy street outside of a department store. ${ }^{1}$

Studies on young people's exposure to IPV have increased during the last few years. Particularly, research interest has focused on measuring the prevalence of IPV, screening its behavioural and mental health consequences and investigating its associated factors. Studies have reported alarmingly high rates of adolescents and young people's exposure to IPV (see, for example Barter et al., 2017), increased risk of short- and long-term behavioural and mental health problems (Barter and Stanley, 2016) and associated risk factors, such as a partner being older (Hellevik \& Øverlien, 2016). In addition to face-to-face physical, psychological and sexual violence, exposure to violence and abuse through social media, such as Instagram and Snapchat, has received increased attention in the literature in the last few years (Barter et al., 2017; Hellevik, 2018).

\footnotetext{
${ }^{1}$ Within this field of research, different concepts of age are used (e.g. adolescents, youth, young people and teenagers). In this study, the participants are 17-23 years old and, therefore, will be consistently referred to as 'youth' and 'young people'. When referring to research where other age-related terms are mentioned, the respective concept will be used. In addition, in the literature, two main concepts are used for violence in young people's relationships: 'youth/teenage intimate partner violence (and abuse) and '(teen) dating violence'. I will use the term youth intimate partner violence (IPV) in this paper, when studies using other terms are not referred to.
} 
Although the number of studies has increased considerably (Barrett, 2015), as noted by Donovan and Hester (2015) and Messinger (2014), there is still a considerable lack of studies on violence and abuse in same-sex relationships, and many questions remain to be answered. I argue that this finding is particularly true for youth victims such as Magnus. ${ }^{2}$ Young people's exposure to IPV in same-sex relationships has been recognized only recently. This recognition may be due to reticence among the LGBTQ community (as suggested by Donavan and Hester [2015] and Irwin [2008]). However, it may also be due to methodological challenges, such as small sample sizes, reluctance among young people to define themselves as gay, lesbian or bisexual and fear of homophobic reactions if consenting to participate in research (McClennen, 2005). However, studies measuring IPV prevalence show that sexual minority youths experienced equal or higher risk for physical dating violence victimization compared with youths who identify themselves as heterosexual (cf. Dank et al., 2014).

A few qualitative studies have been conducted that provide insights into the nature and dynamics of sexual minority youths exposed to IPV. Gillum and DiFluvio (2012) conducted focus groups in the US with 18 sexual minority youths between 18 and 24 years old. The participants described four themes that contributed to IPV in same-sex relationships: homophobia, negotiating stereotypical gender roles, assumed female connection and other relationship issues, such as jealousy. Pentaraki's (2017) study in Northern Ireland on 12 LGBT teenagers between 16 and 22 years old focused on barriers to helpseeking. In six individual and two focus group interviews, the young people identified numerous barriers, such as fear of double disclosure. In a US study, 11 focus groups were conducted on 86 victimized young men who identified themselves as either gay or bisexual. The narratives provided different dynamics of violence, such as escalation into increasingly severe violence over

\footnotetext{
2 The participants in the present study have experienced violence and abuse from their same-sex partners. Therefore, the term 'same-sex partner' will be consistency used in this article. Furthermore, the term 'sexual minority youth' will be used when discussing all youth with sexuality other than heterosexuality. However, when referring to studies where other groups are discussed or where the author uses different terms, these respective terms will be used. Two female informants in this study have had intimate relationships with young men. IPV against bisexuals have received increased attention in the literature (cf. Heimer et al., 2018) and will be addressed when discussing the case of Tone (for a discussion on categories, see Messinger, 2014).
} 
time (Kubicek et al., 2016). In a UK study, Donovan and Hester (2008) interviewed 67 adults with same-sex IPV experiences. In an analysis of the young adults, the authors emphasised the role of the education sector in addressing IPV issues. That is, the young informants lacked embeddedness in the LGBTQ community and knowledge of what to expect in relationships.

However, the US, the UK and Northern Ireland differ from Scandinavia in terms of laws, policies and norms affecting the lives of sexual minority youths. Norway and Sweden are considered "gay-friendly" concerning laws and policies at all levels of society (ILGA, 2015). A recent study conducted in Norway concluded that the number of people with negative attitudes has declined from 20 percent in 2008 to nine percent in 2017 (Bufdir, 2017). However, ignorance and prejudice remain as argued by gay rights groups, such as The Swedish Federation for Lesbian, Gay, Bisexual, Transgender, Queer, and Intersex Rights (RFSL).

Many questions related to the understanding of IPV in sexual minority youths remain uninvestigated to a large extent as most research on young people has treated youth as a homogenous group. This research was conducted to contribute to the expanding knowledge base of IPV by interviewing youths with IPV experiences from their same-sex partners and examining the similarities of their experiences to those in heterosexual relationships. Moreover, this study also aims to shed light on the complicating factors of sexuality. Thus, the following research questions need to be addressed to achieve the aims of this study:

1. What are the young people's experiences of IPV, and how do they understand it?

2. What are the specific challenges related to the issue of IPV, when experienced in same-sex relationships? And how does being young in a heteronormative society impact the IPV experience?

\section{Concepts and Theoretical Framework}

\section{Intimate Partner Violence}

The World Health Organization (WHO) defines IPV as ' ....any behavior within an intimate relationship that causes physical, psychological or sexual harm to those in the relationship' (WHO, 2012: 1). Research on youths with IPV experience has established the issue of digital violence, which is referred to in this study as a form of psychological violence and often with sexual 
connotations (see Øverlien et al., 2019). However, this article shows that one of the complicating factors of IPV is the different interconnections of various forms of violence and abuse, which contribute to multiple forms of contexts and victimhood of IPV.

\section{Youth and Heteronormativity}

Youth is the period between childhood and adulthood, when young people explore opportunities in school, in the workplace and intimate/romantic relationships (Arnett, 2000). During this stage, young people begin to form their identity, for example by finding one's sexual identity. The desire for exploration and greater independence combined with limited experience may also bring young people in vulnerable positions that contribute to risk behaviours, such as extensively using alcoholic substances, experimenting with drugs and meeting strangers online for sexual encounters. In addition, research has found that young people report that they are not taken seriously by adults; that is, their negative experiences, violence and abuse, are not addressed, and their voices are neither heard nor respected (Hellevik et al., 2015).

Sexual minority youths' development of healthy and positive sexuality in a heteronormative society may include discrimination and homophobia, thus making this stage even more challenging (Gillum and DiFulvio, 2012). Their state of being young may place them in an inferior position in addition to being part of sexual minority groups. Heteronormativity recognizes that heterosexuality is the norm, which may not only impact and complicate young people's identity formation but also lead to bullying, ostracism, violence and abuse (Marrow, 2004). In addition, heteronormative beliefs and notions of manhood and womanhood can place sexual minority youths in a vulnerable position (Chung, 2007). Based on the concept of 'minority stress', which is wellstudied in the literature (Meyer, 2003), heteronormativity is one of the main external stressors that may greatly affect the lives of sexual minorities (for a critique, see Donovan and Hester, 2015 Furthermore, when the dominant discourse (understood here as a network of norms expressed through talk), that structure the social organization of society and as a consequence is intimately connected to power, is heteronormative, all other experiences are excluded.

\section{Methods}

The present study is part of two closely related studies on intimate relationships among young people conducted in Sweden and Norway. Safeguarding 
Teenage Intimate Relationships (STIR) is a study of teenage IPV and abuse that includes five European countries, namely, England, Italy, Bulgaria, Cyprus and Norway. ${ }^{3}$ The author of this current study leads the research conducted in Norway (part of STIR) and Sweden. ${ }^{4} \mathrm{~A}$ total of 21 teenagers between 15 and 18 years and 18 young people between 18 and 23 years, all with IPV experiences, were interviewed in the studies in Norway and Sweden, respectively. The same interview guide, with minor adjustments, was used in both countries. One participant informant in Norway and three in Sweden had experienced IPV in a same-sex relationship. The four interviews were selected as data for the present study.

Young people with IPV experiences in heterosexual and, particularly, in samesex relationships can be considered as a 'hard to reach' population. In spite of a large network, support from organizations working with and for sexual minorities, and numerous meetings and contacts with key persons in that community, the researcher experienced serious difficulty recruiting participants. After more than two years of active recruitment, four participants were recruited through a support service for young people, school activity and an advertisement published in a newspaper and on Facebook.

The author and a doctoral student conducted two interviews, respectively, in a location chosen by the participants. To stimulate narratives, 'teller-focused' interviews were applied (Hydén, 2014) using an interview guide organized in themes. As a result, the narratives were explorative rather than informed by theory. That is, the informants were asked to describe their experiences and possible challenges rather than providing them the definitions of such experiences and challenges. The stories told are perceived as co-constructions because they were told in interaction with the interviewer. Hence, they are contextual, fluid and shaped by the time and situation they were told within (Hydén, 2014; Plummer, 1995; Riessman, 1993).

\footnotetext{
3 The study was funded by the DAPHNE III Programme of the European Commission. The Norwegian segment was also funded by the Norwegian Ministry of Children and Families.

4 The study was funded by the Swedish Crime Victim Compensation and Support Authority and Children's Welfare Foundation Sweden.
} 
As a method of analysis, I used the Listening Guide (Doucet and Mauthner, 2008; Gilligan et al., 2003; Woodcock, 2016) and its four stages of analysis. As described by Woodcock (2016), the Listening Guide focuses on uncovering complexities by conducting multiple readings and using different stages of analytical tools. The stages of analysis help uncover the multitude of voicesat times contradicting - that individuals have about their experiences.

I used the Listening Guide in the following manner: stage 1) listening to the plot-the basic grounded theory question was asked, 'What is happening here?' while developing master themes, listening to silences, pauses and changes in voice tone and focusing on my 'reader response'; stage 2) creating I- poemsomitting all texts other than those focused on 'l' (see ingress) to focus on the active ' $l$ ', the narrator of the story and how he/she speaks about himself /herself and his/her social world; stage 3) searching for the relational narrated subjectexploring the subject's social network and his/her relation to other subjects; and stage 4) reading structured subjects-shifting the attention to the power relations described, dominant ideologies and discourses that frame the narrative and the subject's manner of negotiating and positioning him/herself with regard to these power relations.

Stages 1 and 2 were used to bring forward the violence and the subject's understanding thereof (research question 1), whereas stages 3 and 4 were used to identify specific challenges related to the IPV in same-sex relationships (research question 2).

\section{Ethical Considerations}

Ethical considerations were of utmost importance in the two projects. Ethical guidelines were not used as a checklist but were considered throughout the entire project. The participants received written and oral information about the project before deciding whether to participate. The age limits for independent consent are 15 years in Sweden and 16 in Norway, respectively. Thus, all four participants were qualified to give independent consent. The interviewer remained attentive to the risk of over-disclosure, possible distress caused by the interview and ongoing consent (if the participant wished to participate throughout the interview). One criterion for potential participants was that the abusive relationship had ended. Participants' personal identity information, such as names and locations, has been modified. 


\section{Participants}

The four participants, namely, Magnus, Marcus, Camilla and Tone, had experienced IPV in a same-sex relationship, mostly during their first relationship. Camilla and Tone also had relationships with abusive young men. Three of the participants grew up with their biological parents, whereas one, Tone, lived in foster families during most of her life. They lived in the countryside, in medium-sized towns, and on the outskirts of a larger city. Although they have different genders and possibly orientations, they did not want to label themselves. Nevertheless, they all had an intimate relationship that differed from the majority.

At 16 years old, Magnus met Roger, who was 8 years older, through an Internet site. Soon after they began seeing each other, Roger started to control Magnus and check his phone for messages and phone calls. Shortly into the relationship, Roger started to physically, psychologically and sexually abuse Magnus. After five years, Magnus broke up with Roger.

At 14 years old, Marcus met Pontus through the Internet. Pontus was 20 years old then and was sexually violent towards Marcus the first time they met. The sexual violence escalated into severe violence when Marcus was physically injured. The sexual violence was combined with psychological violence. Two years after the breakup, Marcus reported the abuse to the police and Pontus was convicted of sexual abuse of a minor. After their separation, Marcus continued to meet adult men on the Internet and face-to-face, and several were abusive to him.

At 17 years of age, Camilla became acquainted with a girl in school, namely, Hanna, with whom she immediately fell in love. They dated for two years. The abuse started with Hanna's need to control Camilla. The violence took serious physical forms. For instance, Hanna would hold a pillow over Camilla's mouth so she could not breathe. These instances were followed by affectionate actions and care. At the end of their final year of secondary school, Camilla broke up with Hanna. As a result, Hanna told Camilla that she would use all her contacts to ruin Camilla's life.

When Tone was 14 years old, she had a romantic relationship with another girl. Although she described this relationship as 'nice', it was also abusive. After they broke up, she started dating a boy from her school of her same age. Similarly, he was psychologically abusive to Tone throughout their relationship. Finally, Tone broke up with him. However, he publicly shamed her by posting pictures 
of her and her former girlfriend on Facebook, with degrading words and insinuations. The posts quickly filled up with homophobic comments. Tone was bullied after the posting of the pictures and was forced to leave her foster family. Thus, she moved to another family in a new town.

\section{Results}

The results of the four steps of the analysis are presented in this section. Based on the research questions, this section has been divided into two parts, with sub-sections under each part.

\section{Violence and Abuse: Experiences and Understanding}

\section{Voices of Victimization}

The interviews focused on violence and abuse experienced by young people. Thus, various stories about different forms of victimization were gathered. The violence and abuse constituted physical, psychological, digital and sexual violence. These forms of violence and abuse were intertwined in most of the interviews. Magnus was also asked about the type of violence he experienced from Roger. Magnus stated that psychological abuse was more difficult to live with than physical violence:

\footnotetext{
I think the psychological [abuse] was much worse than the physical [violence]; it wore me down, it made me sadder... it happened all the time, while the physical could stop after one day. One week or one month could go by, and then the physical violence happened, but in between there were lots of psychological...I was ugly and disgusting and repulsive: 'I can't believe anyone wants to be friends with you'.
}

As Magnus explained, although the psychological abuse could occur for days, weeks or all the time, the physical and sexual violence could be described as incidents. These incidents took place over longer or shorter periods. Magnus stated that Roger demanded sex, which was always on his terms. However, over time, the abuse increased in frequency and length.

Camilla was asked to describe her relationship with Hanna. Similar to Magnus, Camilla talked about the pain of psychological abuse, jealousy, coercive control and serious physical violent effects of such control:

She [Hanna] made me think it was reasonable that she locked me in the bathroom...she would hold her hand over my mouth when I cried so there would be no sounds, but then I couldn't breathe either, so I got the reflex 
to throw up-once she forced her whole hand into my mouth so that I threw up....and we showered together afterwards since she got my vomit on her... and then suddenly it was all very affectionate again.

The interconnection of different forms of abuse formed a pattern of violence and abuse that can be understood as constant and permeating every part of a person's life. Moreover, the cycle of violence progresses from psychological (making someone think she does not deserve to be heard), to physical (forcing one's hands into another's mouth), to showing remorse and tenderness ('it was all very affectionate again'). This cycle has been described in the literature for more than four decades (see, for example Donovan and Hester, 2015; Kelly, 2004: Walker, 1979). In addition, based on the participants' narratives, access to power can be unequal due to various reasons other than the gender of the abused. In Magnus's case, a difference in age and body size was noted. On the contrary, Camilla's case entailed class and familial financial inequalities. These differences created power imbalances that may have influenced their exposure to violence (see Renzetti [1988] for a discussion on power in same-sex relationships).

\section{Voices of Self-blame and Shame}

Magnus talked about the psychological abuse-a form of violence he described as more difficult to endure than the physical because it "happens all the time"and how the psychological abuse escalated into physical violence. I asked him to narrate a situation when days of psychological abuse ended with a violent episode:

\footnotetext{
Magnus: One day, we went to buy flowers, in a flower shop, and I don't know why we started fighting, but then I was beaten again, down in some bushes. I remember all went black, and then I got the feeling. I was scared to death, but I had gotten used to it. It was almost natural...I was pushed down in some bushes, and he tried to strangle me.

Interviewer: This was outside, in public?

Magnus: Yes, and I felt such incredible shame-you think, what do others who walk by think? I did connect with people, when it happened, when I was laying down in the bushes. People kind of looked at me, and then I thought, I looked at the people who looked at me, laying there, and they wondered 'What kind of person is this?' 'Do they have a relationship? And then just, 'What are you doing, Magnus?' But then, I just kept being with Roger.
}

Budden (2009) emphasised the social nature of shame and argued that shame is the 'quintessential social emotion underlying social threat, comprising a family of negative feelings ranging from mild embarrassment to severe humiliation' ( $p$. 
1033). In addition to his fear of his life, Magnus feared the gaze of the people walking by, which made him feel 'incredible shame'. For victims of violence and abuse, the central components of shame include the feelings of being unable to defend oneself, humiliated and judged by others; humiliation includes having observers witness one's defeat (Andrews et al., 2000). This feeling of shame was worsened by Magnus's self-directed question, 'What are you doing, Magnus?' This question did not result in a reaction that changed his situation, such as Magnus leaving the abusive partner, but resulted in Magnus staying with his partner.

Shame, self-blame and guilt are emotions frequently discussed in the literature on IPV. Although it may seem unreasonable, victims of violence and abuse may self-blame for being unable to protect themselves and their family from the abuse, and causing the abuse or staying in situations where abuse is likely to occur (Kubany \& Watson 2003). After ending his relationship with Pontus, Marcus described how he met different older men, dated them and was repeatedly abused sexually. Although blaming them for the abuse, Marcus also self-blamed for 'exposing himself' to the risks of contacting people online and then meeting them for dates, sometimes in places away from his family and hometown.

I exposed myself, I can't accuse anyone for what happened, for the abuse-quite some time after. I had the attitude that I deserved it, kind of...it was something I chose to expose myself to. I am not sure why, but perhaps as a way to process what I had been through.

\section{Voices of Resistance}

Parallel to any story of victimization is a story of resistance (Wade, 2001; Cavanaugh, 2003). When Tone's boyfriend posted pictures of her and her former girlfriend with homophobic comments on social media, Tone was judged with hateful and sexist comments from others. She wrote to him and said, 'If you continue doing this, I will report you to the police for harassment, bullying and extortion':

Magnus's boyfriend, Roger, would check his phone every time they met as he did not allow Magnus to contact other males on social media.

When I was not with him I downloaded Snapchat and stuff, and then when I was to meet him I was like, 'Remember to erase all text messages, take off all apps from the phone, take away this and that'. I had a list in my mind of all the things to take away...' 'l am going to check your phone' [in a different voice]. 'But why do you have to do that?', 'Don't question me' [in a different voice]. 'Oh, okay'. 
Magnus would erase everything on his phone that could anger Roger. He would then download the applications immediately after leaving Roger's apartment and continue having contact with other individuals, particularly other men. Although Magnus was pleased for 'tricking' Roger, he also expressed how Roger's constant coercive control caused great stress in his everyday life.

\section{Challenges Related to IPV in Same-sex Relationships}

The third stage in the analysis requires 'reading for relational narrated subjects' according to Doucet and Mauthner (2008), whereas the fourth step requires 'reading for structured subjects'. When these stages were applied, all data describing the participants' social relations and immediate networks and their understanding of their experiences in relation to power structures and dominant discourses were analysed. The analysis shows that numerous challenges were specifically related to IPV in same-sex relationships.

Responses from Network: The Interconnection between Sexuality and Abuse

The four young participants described having supportive, unsupportive, and hostile social relations in regard to both their sexuality and their exposure to violence. They had been open about their sexuality at an early age and had already 'come out' when they were victimized. However, their family, close friends and classmates' responses to their sexuality and deliberate and nondeliberate 'coming out' were intertwined with their partners' abuse that they experienced. At the time of victimization, the four informants were teenagers. Their parents' responses to their same-sex partner and victimization were significant to them.

The participants described a mix of reactions from friends and classmates when they admitted that they were attracted to their same sex. When Magnus told his closest friends that he was gay, he was nervous about their response. This experience could be interpreted as Magnus's fear of rejection. However, they 'laughed a little; they knew it sort of, and I didn't mind them saying that they knew it; it was just a relief'. For the parents of three of the participants, the concern was that, as mentioned by Magnus, 'they would never become grandparents'. The reactions from Camilla's parents were stronger as they questioned her choice of a girl as a partner 'when you could have any boy you want'. In addition, Camilla chose a girl who is 'not so...feminine, she didn't care about her appearance....she was very much of a rebel'. In her investigation of 
young women's experiences of dating violence, Chung (2007) argued that femininity can be expressed only in relation to a male in a heteronormative discourse on intimate relationships. According to her parents, Camilla could have any boy she wanted. She may be understood as giving up part of her femininity by choosing a girl, who is 'not so feminine', making her choice even more problematic.

However, the reactions from their classmates were significantly more hostile. Magnus and Marcus described how they were abused and expelled from locker rooms by other boys when they found out that Magnus and Marcus were attracted to males. In the following, Marcus describes his experience when rumours spread that he had had intimate relations with an older boy when he was 14 years old.

Junior high was tough. I lost about half of my group of friends...they were gone in a heartbeat...I was expelled from the school locker rooms for the rest of junior high.

Magnus had similar experiences:

I was chased home from school, and stuff like that-I was abused in school, in the locker rooms and other places...

Tone also experienced strong homophobic responses from classmates and other young people in the community. She had this to say regarding her exboyfriend's posts on social media about her and her former girlfriend:

\begin{abstract}
He made a [public] Facebook group...the group was targeted against me and her [her former girlfriend] and the thing was...we were going to a birthday party....we were four girls, they took pictures of her and me. It was really fun. We had done our makeup and put nice clothes on, and then he said I slept with these girls in the bathroom...I had had enough. I really struggled [mentally]. I have had trouble trusting people since then...that is one of the reasons I couldn't live there anymore.
\end{abstract}

As mentioned earlier, the homophobia became so severe that Tone had to move to another foster family in another town.

In her interview, Tone mostly focused on the abuse from her former boyfriend using her bi-sexual identity against her. In recent literature reviews, Heimer et al (2018), as well as Messinger (2014), direct their focus on young bisexuals' vulnerabilities to IPV, as studies have shown a particularly high prevalence of violence and abuse, both from same-sex partners and opposite-sex partners. As noted in Heimer et al. (2018), one of the complexities may be the opposite partner's homophobic views. In Tone's case, this complexity made her vulnerable to new abuse. 
The participants reported positive responses from their closest friends. However, they also experienced being questioned, particularly by negative responses from parents, and ostracized in school. These experiences made them perceive themselves as a burden to their closest family. This perception played an important part in their victimization by their intimate partners.

After Marcus explained his 'tough time in junior high', the interviewer asked about his parents' response to the incident. He replied:

My younger brother had some medical issues, and my mother had just lost her job, so didn't want to burden my family even more [with his sexuality]. I guess that was kind of stupid, but there and then, I didn't want to cause any more trouble, and that went on for quite some time... and some of the reason[s] why I got involved with him [the violent boyfriend] was to confide in someone who was not family, sort of...and I bitterly regretted that afterwards.

In this narrative, Magnus describes how his feeling of 'not wanting to cause any more trouble' drove him to search for someone who could care for and understand him as a 14-year-old. In this context, 'trouble' is interpreted to refer to his sexuality and attacks experienced in school, in addition to the trouble at home, that is, his brother's illness and mother's unemployment.

Similar to Marcus, Camilla talked about her sexuality as a burden to her family and social networks. Although she acknowledged saying 'We never felt resistance [from the surrounding society]. No one was saying we were disgusting or anything', she stated that:

I still felt that I was different and that I had already pulled my card, and if I, besides being in a lesbian relationship, also was together with a girl who abused me, there was no way I would have had the courage to tell anyone about that.

A phenomenon discussed in the literature on sexual minorities and IPV referred to as 'double disclosure' is relevant to this experience. That is, disclosing violence indirectly requires disclosure of the same-sex partner, which can constitute a barrier to help-seeking (Donovan and Hester, 2015; Pentaraki, 2017). In Camilla's case, her attraction to females and relationship with a girl was already known; hence, she had 'come out'. Nevertheless, as she understood this identity as a burden to her immediate social networks and social relations, she found it difficult to place another burden upon them, that is, being victimized by her girlfriend. Thus, this situation became a barrier to helpseeking, where she did not tell anyone about the abuse until the relationship was over. 


\title{
Dominant Discourses Render the Violence Invisible
}

In line with Gillum and DiFulvio (2012), the participants in this study shared ideas that violence and abuse are events that are happening in heterosexual relationships. It could be argued that youths, including sexual minority youths, growing up in a heteronormative society perceive violence as gendered; that is, men are the main perpetrators of violence against women. As a result, victimized sexual minority youths may not define their experience as violence and abuse (Donovan \& Hester, 2015; Heimer et al., 2018; Holmberg \& Stjernqvist, 2005). As Camilla explained:

\begin{abstract}
If I would have been with a guy, it would have been so much easier to make it visible to myself. I think...there is so much talk about men's violence against women, and I sort of didn't know that there could be violence in same-sex relationships, or I didn't reflect upon that. So all the time, I made excuses such as 'well, she is not feeling well'.
\end{abstract}

She continues:

Violence committed by women is not something you really talk about 'cause it is not a structural problem in the same way, and I guess I sort of didn't know that women could behave like that.

As described here by Camilla, the discursive constraint, that it is men who are abusive to women, caused Camilla to define her negative experiences in the relationship as events not related to violence and abuse. Camilla's girlfriend was struggling mentally. Thus, Camilla perceived this behaviour in the context of mental difficulties. However, the dominant social discourse on men's violence against women may also impact professionals' tendencies to ask about violence or define what is taking place as violence and abuse. Magnus and Roger went to a few sessions of couples counselling when Magnus was in his last year of high school. Magnus told the counsellor about the violence, but she failed to address it. As Magnus stated, 'It is the norm that it is the man that abuses the woman'. This norm may have had a bearing on what role the perpetration of violence had in the counseling of the young couple.

\section{Discussion}

The first two stages of analysis in this article focused on answering the question 'What is happening here', identifying themes and creating I poems. These stages uncovered stories similar to those investigated by researchers of heterosexual violence. These stories narrate physical, psychological, digital and sexual violence as well as self-blame, shame and resistance. Important dynamics of violence are aspects such as power imbalances, escalation of 
violence and the overlapping of different forms of violence. As noted by researchers such as Holmberg et al. (2005), Messinger (2014) and Heimer et al. (2018), the nature and dynamics of IPV in heterosexual and same-sex relationships are similar. However, the complicating factor of sexuality grounded in a heteronormative society becomes evident when stages three and four of the analysis were conducted to explore responses from immediate social networks and social relations and dominant ideologies and discourses. Here, Meyer's (2003) concept of 'minority stress' becomes central, as the young person's experience of heteronormativity becomes another layer of stress, in addition to the stress evoked by being subjected to violence and belonging to a sexual minority. Homophobic exposure in school may lead to ostracism and being cast as deviant. This experience may force a young person to seek support elsewhere, which may result in detrimental consequences due to their limited experiences. If the young person has limited support from home or feels rejected by parents and peers, their feelings of being different and the risk of seeking support from people who will abuse them increase. Furthermore, limited support and rejection from the young person's peer network could lead to serious consequences on the dynamics of intimate relationships and abuse. That is, young couples may isolate themselves. This situation could constitute another barrier to help-seeking. It also underlines the importance for schools and other professional arenas to disclose the abuse and provide support.

Furthermore, the participants in the study have helped shed light on the issue of feeling like a burden to one's immediate social network and its negative consequences, including being a barrier to help-seeking. If identifying as a gay, lesbian or bisexual is a burden to one's family or leads to problems in school, such as being attacked in locker rooms, a young person may feel that revealing that he/she is also being victimized by an intimate partner represents an additional burden. Thus, the young person may feel this scenario is impossible to place on those who care for him/her. Based on the literature (see, for example Øverlien et al., 2019), young people who experience violence and abuse are particular about who they disclose to. They are reluctant to disclose their experience of violence to someone who may not be able to 'contain' their story. This study found that society's heteronormative understanding of violence as acts perpetrated by men against women could become a barrier to help-seeking due to two reasons. First, others may not identify undesirable events in the relationship as violence. Second, the victim may not identify the negative aspects of the relationship as violence and abuse. 
The participants' experiences described in this study need to be understood within the context of their age. Particularly, they are young people with commonalities shared by others in their age group, regardless of sexuality. Furthermore, they were all in their teenage years when they experienced abuse. This stage is a time for identity formation, exploration and striving for greater independence. As studies on poly-victimization have shown, multiple exposures to various victimizations lead to serious harmful implications for children and adolescents (Finkelhor et al., 2007). Exposure to violence and abuse in one's first intimate relationship while also enduring hostility, rejection and severe violation because of one's newly discovered identity may negatively impact one's relationships, mental health, school performance and ability to work.

The complexities described were possible to uncover by using a method of analysis, the Listening Guide methodology, that allowed for repeated readings of the same data using different lenses and focusses of attention. For example, the creation of I poems established the subjective position, whereas 'reading for structured subjects' shifted the lens towards power relations and the subject's position thereof. The method is time-consuming and not suitable for large datasets, and requires rich interview data.

\section{Conclusion}

This study shows that although victims of IPV in heterosexual and same-sex relationships have several similarities, contextual challenges create unique conditions and vulnerabilities for IPV experienced by the LGBTQ community that are not shared by heterosexual individuals. Hence, qualitative studies are required to help us understand the dynamics of violence in intimate relationships among sexual minorities. Similarly, other marginalized groups may have specific patterns that may not be shared with the majority and thus also need to be explored qualitatively. Furthermore, future studies should differentiate between different groups of violence-exposed sexual minority youths.

Finally, professionals, such as social workers, need to gain knowledge of the unique challenges and strengths of sexual minority youths exposed to IPV. As argued by Barrett (2015), professionals' acceptance of the LGBTQ's identities is not sufficient. They must be 'engaging in active efforts to reinforce the validity of LGB identity' by 'exploring the impacts of heterosexism and homophobia on LGB persons' (p. 32) as well as affirming and working with the unique strengths and resilience of the LGBTQ community. Furthermore, we need professionals who actively ask youth about experiences of violence and abuse in their 
relationships and whether the youth confirms that he/she has been abused or abusive. These experiences need to be validated and taken seriously. Moreover, as noted by Donovan and Hester (2008), school is an important site for interventions in disclosing and reporting IPV in addition to addressing issues such as injustice, homophobia and discrimination and introducing alternative sexualities and relationships. The lives of young people can greatly improve with the help of professionals, researchers, NGOs and policymakers who need to acknowledge sexual minority youths by promoting IPV prevention, implementing improved policies and providing better support for this group.

\section{References}

Andrews, B., Brewin, C. R., Rose, S., \& Kirk, M. (2000). Predicting PTSD symptoms in victims of violent crime: The role of shame, anger, and childhood abuse. Journal of Abnormal Psychology, 109(1), 69-73. https://doi.org/10.1037/0021843X.109.1.69

Arnett, J. J. (2000). Emerging adulthood. A theory of development from the late teens through the twenties. American Psychology, 55(5), 469-80. https://doi.org/10.1037/0003-066X.55.5.469

Barrett, B. J. (2015). Domestic violence in the LGBT community. Retrieved January 2, 2019,

from http://oxfordre.com/socialwork/view/10.1093/acrefore/9780199975839.001.0001 lacrefore-9780199975839-e-1133 https://doi.org/10.1093/acrefore/9780199975839.013.1133

Barter, C., Stanley, N., Wood, M., Lanau, A., Aghtaie, N., Larkins, C., \& Øverlien, C. (2017). Young people's online and face-to-face experiences of interpersonal violence and abuse and their subjective impact across five european countries. Psychology of Violence, 7(7), 375-384. https://doi.org/10.1037/vio0000096

Barter, C., \& Stanley, N. (2016). Inter-personal violence and abuse in adolescent intimate relationships: mental health impact and implications for practice. International Review of Psychiatry, 28(5), 485-503. https://doi.org/10.1080/09540261.2016.1215295

Budden, A. (2009). The role of shame in posttraumatic stress disorder: A proposal for a socio-emotional model for DSM-V. Social Science and Medicine, 69(7), 10321039. https://doi.org/10.1016/j.socscimed.2009.07.032

Bufdir (2017). Attitudes against Ihbtiq-persons. Retrieved January 28, 2019, from https://www.bufdir.no/Statistikk_og_analyse/lhbtiq/Holdninger/

Cavanaugh, K. (2003). Understanding Women's Responses to Domestic Violence. $\begin{array}{llll}\text { Qualitative Social } & \text { Work, 229-249. }\end{array}$ https://doi.org/10.1177/14733250030023002

Chung, D. (2007). Meaning making of relationships. Young women's experiences and understanding of dating violence. Violence Against Women, 13(12), 1274-1295. https://doi.org/10.1177/1077801207310433

Dank, M., Lachman, P., Zweig, J. M., \& Yahner, J. (2014). Dating violence experiences of lesbian, gay, bisexual, and transgender youth. Journal of Youth Adolescence, 43, 846-857. 
Dobash, R., \& Dobash, R. (1980). Violence against Wives: A case against the Patriarchy. Open Books, London.

Donovan, C., \& Hester, M. (2015). Domestic Violence and Sexuality: What's Love Got to Do with It? Bristol: Policy Press. https://doi.org/10.1332/policypress/9781447307433.001.0001

Donovan C., \& Hester M. (2008). 'Because she was my first girlfriend, I didn't know any different': making the case for mainstreaming same-sex sex/relationship education. Sex Education 8(3), 277-287 https://doi.org/10.1080/14681810802218155

Doucet, A., \& Mauthner, N. S. (2008). What can be known and how? Narrated subjects and the Listening Guide, Qualitative Research 8(3), 399-409.

Finkelhor, D., Ormrod, R. K., \& Turner, H. A. (2007). Poly-victimization: A neglected component in child victimization. Child Abuse and Neglect 31(1), 7-26. https://doi.org/10.1016/j.chiabu.2006.06.008

Gilligan, C., Spencer, R., Weinberg, M. K., \& Bertsch, T. (2003). On the Listening Guide: A Voice-Centered Relational Method. In P. Camic, J. Rhodes, \& L. Yardley (Eds.), Qualitative Research in Psychology: Expanding Perspectives in Methodology and Design (pp. 157-172). Washington DC: American Psychological Association. https://doi.org/10.1037/10595-009

Gillum, T.L., \& DiFulvio, G. (2012). "There's so much at stake”: Sexual minority youth discuss dating violence. Violence Against Women, 18, 725-745. https://doi.org/10.1177/1077801212455164

Heimer, G., Sandell, K., \& Sundström, M. (2018). Våld mot hbtq-personer - en forsknings- och kunskapsöversikt [Violence against persons defining as lgbt: a Research- and knowledge overview]. Uppsala University, Sweden: The National Center for Knowledge on Men's Violence Against Women.

Hellevik, P., \& Øverlien, C. (2016). Teenage intimate partner violence: Factors associated with victimization among Norwegian youths. Scandinavian Journal of Public Health, 44(7), 702-708. https://doi.org/10.1177\%2F1403494816657264

Holmberg, C., \& Stjernqvist, U., \& Sørensen, E. (2005). Våldsamt lika och olika: om våld $i$ samkönade parrelationer [Alike and different: on violence in same-sex relationships]. Stockholm, Sweden: Stockholms universitet.

Hydén, M. (2014). The teller-focused interview: Interviewing as a relational practice. Qualitative Social Work, 13(6), 795-812. https://doi.org/10.1177/1473325013506247

ILGA Europe. (2016). Country Ranking. Retrieved February 1, 2019, from http://rainboweurope.org/country-ranking

Irwin, J. (2008). (Dis)Counted Stories. Domestic Violence and Lesbians. Qualitative Social Work, 7(2), 199-215. https://doi.org/10.1177/1473325008089630

Kelly, V. A. (2004). Psychological Abuse Of Women: A Review Of The Literature. The Family Journal: Counseling and Therapy For Couples and Families, 12(4), 383388. https://doi.org/10.1177/1066480704267234

Kubany, E. S., \& Watson, S. (2003). Guilt: Elaboration of a Multidimensional Model. The Psychological record, 53(1), 51-90.

Kubicek, K., McNeeley, M., \& Collins, S. (2016). Young men who have sex with men's experiences with intimate partner violence. Journal of Adolescent Research, 3, 143-175. https://doi.org/10.1177/0743558415584011 
Marrow, D. F. (2004). Social work practice with gay, lesbian, bisexual and transgender adolescents. Families in Society, 85, 91-99. https://doi.org/10.1606/1044$\underline{3894.246}$

Messinger, A. M. (2014). Marking 35 Years of Research on Same-Sex Intimate Partner Violence: Lessons and New Directions. In: Peterson D and Panfil VR (eds) Handbook of LGBT Communities, Crime, and Justice. New York, NY: Springer New York, pp. 65-85. https://doi.org/10.1007/978-1-4614-9188-0_4

McClennen, J. (2005). Domestic Violence Between Same Sex Partners. Journal of $\begin{array}{lll}\text { Interpersonal } \quad \text { Violence, } & \text { 149-154. }\end{array}$ https://doi.org/10.1177/0886260504268762

Meyer, I. H. (2003). Prejudice, social stress, and mental health in lesbian, gay, and bisexual populations: Conceptual issues and research evidence. Psychological Bulletin, 129, 674-697. https://doi.org/10.1037/0033-2909.129.5.674

Øverlien, C., Hellevik, P. M., \& Korkmaz, S. (2019). Young Women's Experiences of Intimate Partner Violence - Narratives of Control, Terror, and Resistance. Journal of Family Violence, 1-12. https://doi.org/10.1007/s10896-019-00120-9

Pentaraki, M. (2017). Fear of double disclosure and other barriers to help seeking: an intersectional approach to address the needs of LGBT teenagers experiencing teenage relationship abuse. In Holt, S, Øverlien, C and Devaney J (eds) Responding to Domestic Violence: Emerging Challenges for Policy, Practice and Research in Europe. London. UK, Jessica Kingsley Publishing.

Plummer, K. (1995). Telling Sexual Stories: Power, Change and Social Worlds. London: Routledge.

Renzetti, C. M. (1988). Violence in lesbian relationships: A preliminary analysis of causal factors. Journal of Interpersonal Violence, 3(4), 381-399. https://doi.org/10.1177/088626088003004003

Riessman, C. (1993). Narrative Analysis. Newbury Park, CA: Sage.

Wade, A. (1997). Small acts of living: everyday resistance to violence and other forms of resistance. Contemporary Family Therapy, 19, 23-39.

Walker, L. E. (1979). The Battered Woman. New York: Harper and Row.

WHO. (2012). Understanding and addressing violence against women: Intimate partner violence. Retrieved from World Health Organization: http://apps.who.int/iris/bitstream/10665/77432/1/WHO_RHR_12.36_eng.pdf

Woodcock, C. (2016). The Listening Guide: A How-To-Approach on Ways to Promote

Educational Democracy. International Journal of Qualitative Methods, 15(1): 110. https://doi.org/10.1177/1609406916677594 